\title{
Cross Sectional Study of Zinc, Copper and Magnesium Levels in Preeclampsia and Normal Pregnancy
}

\author{
Balaji B R $\mathbf{R}^{1}$, N Pujari ${ }^{2}$ \\ ${ }^{1}$ M.D.Student, ${ }^{2}$ Professor and HOD, Department of Biochemistry, Government Medical College, Miraj \\ Corresponding Author: Balaji B R
}

\begin{abstract}
Preeclampsia is a pregnancy related high blood pressure disorder. It involves defective trophoblast invasion and decreased spiral artery remodelling. Alterations in micronutrients have been identified as one of the risk factor of preeclampsia. In this study we have estimated the levels of zinc, copper, iron and magnesium in preeclampsia and normal pregnant women. Our study revealed a significant decrease of zinc, copper and magnesium levels and significant increase of iron levels in preeclampsia compared to normal pregnant women. Thus assessment of micronutrients in pregnancy helps in decreasing the incidence of preeclampsia.
\end{abstract}

Keywords: Preeclampsia, Zinc, Copper, Iron, Magnesium

\section{INTRODUCTION}

Preeclampsia is defined as a triad of hypertension, proteinuria and edema occurring after 20 weeks gestation in previously normal women. It is characterized by increased maternal systolic blood pressure $\geq 140 \mathrm{~mm}$ of $\mathrm{Hg}$ and diastolic blood pressure $\geq 90 \mathrm{~mm}$ of $\mathrm{Hg}$ measured on two occasions with the gap of at least 6 hours. It may be associated with proteinuria, $\geq 0.3 \mathrm{~g}$ of protein in 24 hours urine sample ${ }^{[1]}$. The pathophysiological mechanism is still unknown; however risk factors such as obesity, diabetes mellitus, calcium deficiency, advanced maternal age, oxidative stress, placental ischemia, genetics and immune maladaptation have been identified. It is a two stage disorder, the first stage is characterized by an altered formation of placenta and the second stage is the appearance of clinical manifestations of preeclampsia such as hypertension and proteinuria and edema occurring after 20 weeks of gestation. According to National Health Portal of India, incidence of preeclampsia in pregnant women is reported to be $8 \%$ to $10 \%^{[2]}$. Many studies have reported an increase in lipid peroxidation and a decrease in antioxidant capacity in preeclampsia.

Micronutrients such as copper, zinc, magnesium, manganese and selenium are involved in the antioxidant defence mechanism $^{[3]}$. Copper is an essential component of numerous metalloenzymes and cofactor for the antioxidant enzyme superoxide dismutase, catalase and cytochrome oxidase. It is involved in metabolic reactions, angiogenesis, oxygen transport and antioxidation ${ }^{[4]}$. Zinc counteracts oxidation through binding sulphydryl groups in proteins and by occupying binding sites for iron and copper in lipids, proteins and DNA. Zinc is also involved in the synthesis of deoxyribonucleic acid and ribonucleic acid [5]. Iron is essential to all cells but the amount of iron required by individual tissues varies during development. At the same time body must protect itself from free iron, which is highly toxic. Increased levels of free iron are capable of generating free 
radicals that causes cell damage. Alteration of iron status is related to increased oxidative stress and endothelial dysfunction. Increased oxidative stress is catalyzed in presence of free transitional metal ions, particularly iron. Iron species could be a factor in generation of oxidative stress in preeclampsia ${ }^{[6]}$. Magnesium has been known as essential cofactor for many enzyme systems. It also plays an important role in neurochemical transmission and peripheral vasodilatation. Magnesium sulphate appears to be safe effective for the prevention of seizures and has been used as the drug of choice in severe eclampsia ${ }^{[7]}$.

This study was conducted to estimate and compare zinc, copper and magnesium levels in preeclampsia patients and normal pregnant women and to correlate the association of zinc, copper and magnesium levels in preeclampsia.

\section{MATERIALS AND METHODS}

Study design: Cross sectional study

Place of study: Government Medical College, Miraj.

Sample size: 276

Study period: March 2020 to December 2020

Study group: This study was conducted in 138 patients diagnosed with preeclampsia and 138 normal pregnant women. Subjects were enrolled based on inclusion and exclusion criteria. Subjects with underlying medical conditions like diabetes, chronic hypertension, cardiovascular diseases were excluded. Blood samples were collected from participants under proper universal precautions. Collected samples were processed by fully automated analysis method in the Biochemistry lab. Institutional Ethical committee approval and informed consent from participants was obtained before the study.

\section{Statistical analysis}

Data was analysed using SPSS software. All the characteristics were summarized descriptively using the summary statistics of mean and standard deviation (SD). The analysis was performed by independent $\mathrm{T}$ test to observe the significant difference between groups.

\section{RESULTS}

In this study 276 participants were included. Out of them 138 participants were cases and 138 participants were controls. The mean zinc, copper and magnesium levels in preeclampsia and normal pregnancy were $37.7 \pm 3.6 \mu \mathrm{g} / \mathrm{dl}, 47.1 \pm 4.4$ $\mu \mathrm{g} / \mathrm{dl}, 0.93 \pm 0.2 \mathrm{mg} / \mathrm{dl}$ and $86.3 \pm 7.8 \mu \mathrm{g} / \mathrm{dl}$, $93.8 \pm 7.3 \mu \mathrm{g} / \mathrm{dl}, 2.0 \pm 0.4 \mathrm{mg} / \mathrm{dl}$ respectively.

Table 1: Comparison of Zinc, Copper, Iron and Magnesium levels between cases and controls

\begin{tabular}{|l|c|c|c|c|}
\hline \multicolumn{1}{|c|}{ Parameters } & $\begin{array}{c}\text { Cases }(\mathbf{n}=\mathbf{1 3 8}) \\
\text { Mean } \pm \text { SD }\end{array}$ & $\begin{array}{c}\text { Controls }(\mathbf{n}=\mathbf{1 3 8}) \\
\text { Mean } \pm \text { SD }\end{array}$ & T value & P value \\
\hline Serum Zinc $(\mu \mathrm{g} / \mathrm{dl})$ & $37.75 \pm 3.86$ & $87.37 \pm 7.37$ & 70.017 & $<0.0001$ \\
\hline Serum Copper $(\mu \mathrm{g} / \mathrm{dl})$ & $47.23 \pm 4.16$ & $94.41 \pm 8.09$ & 60.942 & $<0.0001$ \\
\hline Serum Iron $(\mu \mathrm{g} / \mathrm{dl})$ & $184.29 \pm 5.53$ & $96.30 \pm 8.54$ & -101.619 & $<0.0001$ \\
\hline Serum Magnesium $(\mathrm{mg} / \mathrm{dl})$ & $0.96 \pm 0.27$ & $2.03 \pm 0.48$ & 22.931 & $<0.0001$ \\
\hline
\end{tabular}

Values are expressed as mean \pm SD (Standard Deviation). Results are presented as P values by independent $\mathrm{T}$ test. p<0.001-Highly significant, $\mathrm{p}<0.01$-Significant, $\mathrm{p}<0.05$ - Statistically Significant, NS-Not Significant

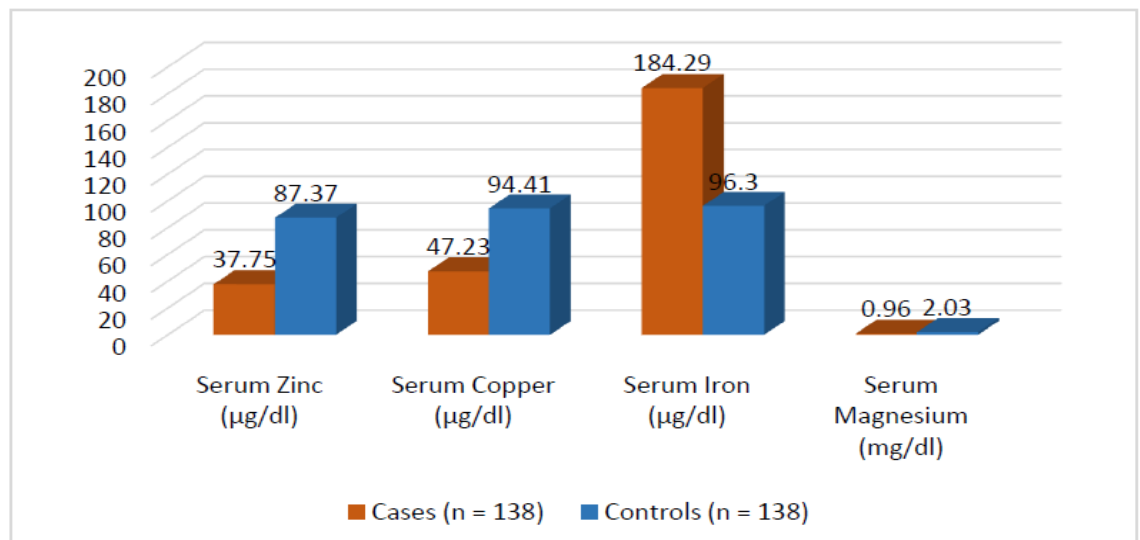

Chart 1: Comparison of Zinc, Copper, Iron and Magnesium levels between cases and controls 


\section{DISCUSSION}

In this study, a total of 276 participants were included. Out of them 138 participants were cases and 138 participants were controls. Result obtained from this study show a significant decrease in serum zinc, copper, magnesium levels and significant increase in iron levels in preeclampsia patients compared to normal pregnant women

Previous studies by Kumru et al. has found significantly lower levels of copper and lower zinc and calcium levels in preeclamptic women compared to healthy controls. They concluded that measurement of these elements may be useful for the early diagnosis of a preeclamptic condition $^{[4]}$. Ugwuja et al. in a study from Nigeria found lower plasma zinc and copper levels in preeclampsia women than normal pregnant women with a significantly lower copper levels ${ }^{[5]}$. Similarly, Akinloye et al. in his study from western Nigeria found significantly lower levels of zinc and copper in women with preeclampsia ${ }^{[6]}$. Ikgoz et al. found zinc and copper levels in the placental tissue of preeclamptic women to be lower than those in healthy pregnant women ${ }^{[8]}$. Jain et al. showed that the mean zinc levels were significantly reduced in preeclamptic group when compared with healthy group ${ }^{[9]}$. Siddiqui et al. also revealed that serum ferritin and serum iron concentration were significantly higher in preeclamptic women in comparison to normal pregnant women [10]. Kristers $\mathrm{K}$ et al, 2011 studied that Magnesium deficiency causes hemodynamic abnormalities such as arterial wall thickening, abnormal vascular tone and endothelial dysfunction ${ }^{[11]}$. Low maternal serum calcium and magnesium concentrations among preeclamptics were found by Kanchapan and Phupong ${ }^{[7]}$.

Inadequate dietary intakes with deficient nutrients have been identified to cause significant health problems in women of reproductive age group, especially in developing countries. This deficiency further increases during pregnancy.

\section{CONCLUSION}

In this study we have concluded that deficiency of zinc, copper and magnesium results in preeclampsia. It implicates a possible role in the development and pathogenesis of preeclampsia. Inadequate dietary intake and improper nutrition may lead to micronutrient deficiencies. Thus analysis of serum zinc, copper, iron and magnesium levels in early pregnancy may help in decreasing the risk of preeclampsia.

\section{Acknowledgement: None}

\section{Conflict of Interest: None}

\section{Source of Funding: None}

\section{Ethical Approval: Approved}

\section{REFERENCES}

1. Roberts JM, Lain KY. 2002. Recent insights into pathogenesis of preeclampsia. Placenta 23:359-72.

2. Black RE. Micronutrients in pregnancy. $\mathrm{Br} \mathbf{J}$ Nutrition 2001; 85: 93-197.

3. Omar Elind A-H. Trace elements as potential biomarkers of Preeclampsia. ARRB.2016;9(1):1-10.

4. Kumru S, Aydin S, Simsek M. Comparison of serum copper, zinc, calcium and magnesium levels in preeclamptic and healthy pregnant women. Biol Trace Elem Res, 2003; 94:105-12.

5. Ugwuja EI, Ejikeme BN, Ugwu NC, Obeka NC, Akubugwo EI, Obidoa O. Comparison of plasma copper, iron and zinc levels in hypertensive and nonhypertensive pregnant women in Abakaliki, South Eastern Nigeria. Pak J Nutr. 2010;9(12):1136-40.

6. Akinloye O, Oyewale OJ, Oguntibeju OO. Evaluation of trace elements in pregnant women with pre-eclampsia. Afr J Biotechnol. 2010;9(32):5196- 202

7. Sukonpan K, Phupong V. Serum calcium and serum magnesium in normal and preeclamptic pregnancy. Arch Gynecol Obstet2005;273:12-6

8. Ikgoz SA, Harma M, Harma M, Mungan G, Can M, Demirtas S. Comparison of angiotensin-converting enzyme, malonaldehyde, zinc and copper levels in pre-eclampsia. Biol Trace Elem Res. 2006; $13: 1-8$. 
Balaji B R et.al. Cross sectional study of zinc, copper and magnesium levels in preeclampsia and normal pregnancy

9. Jain S, Sharma P, Kulshreshtha S, Mohan G, Singh S. The role of calcium, magnesium, and zinc in preeclampsia. Biol Trace Elem Res. 2010;133:162-70.

10. Siddiqui IA, Jaleel A, Kadri H.M.F.A., Saeed WA,TamimiW. Iron status parameters in preeclampsia, Arch Gynecol Obstet 2010: $1728-32$.

11. Kisters K, Barenbrock M, Louwen F, Hausberg M, Rahn KH, Kosch M. Membrane, intracellular, and plasma magnesium and calcium concentrations in preeclampsia. Am J Hypertens 2000; 13: 765- 9

How to cite this article: Balaji B R, K N Pujari. Cross sectional study of zinc, copper and magnesium levels in preeclampsia and normal pregnancy. International Journal of Research and Review. 2021; 8(10): 33-36. DOI: https://doi.org/10.52403/ijrr.20211006 